\title{
ENHANCEMENT OF THE PERFORMANCE OF A SUPERCONDUCTING GENERATOR USING FACTS
}

\author{
G. A. Morsy \\ H. A. Khattab \\ S. M. Osheba \\ A. Kinawy \\ Electrical Engineering Department, Faculty of Engineering, \\ Minoufiya University, Shebin El-Kom, Egypt
}

\begin{abstract}
The paper presents a technique for improving the performance of a superconducting generator (SCG). The technique is based on combining the effects of a fuzzy logic controller (FLC) and a thyristor controlled static reactive power compensator (TCSR). The fuzzy controller requires two input signals and generates the output control signal. This signal is applied at the governor control loop of the SCG in order to accomplish a satisfactory damping for the SCG low frequency oscillations over a wide range of operating conditions. The TCSR is applied at the generator terminal bus bar to change the transmission system configuration, based on a controlled firing angle, for improving the system stability. The performance of the SCG equipped with fuzzy logic controller (FLC) has been studied and the results were obtained in a comparative form with and without using TCSR. The results clearly reveal that inclusion of the TCSR is very significant to improve the system performance and to increase the power transfer capabilities.

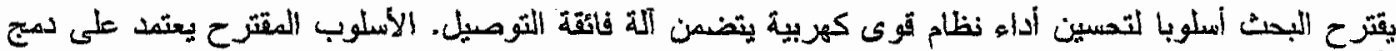

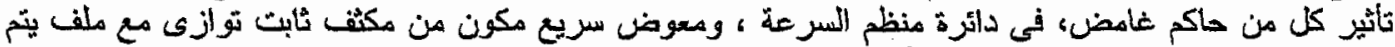

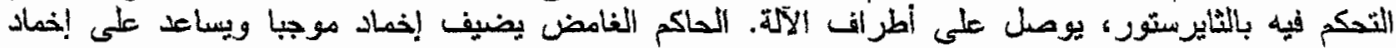

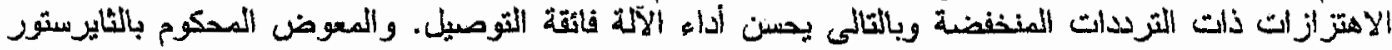

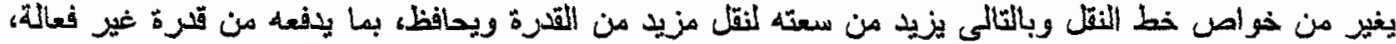

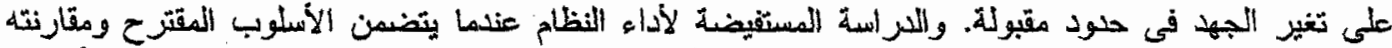

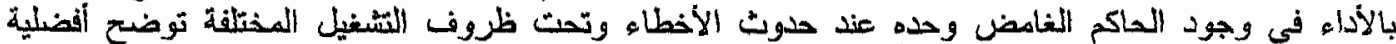

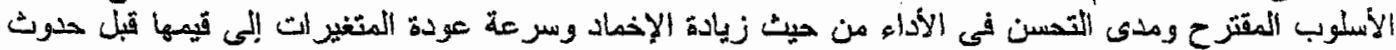

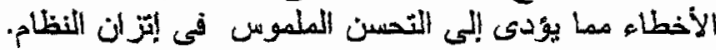

Keywords: Power system control, Superconducting generator, Flexible AC Transmission System (TCSR).

\section{INTRODUCTION}

Power systems need to be continuously expanded and upgraded to cater the ever growing power demand. In recent years, power system planners have faced numerous difficulties in adding new power stations and transmission lines. In view of new generating stations the superconducting generators (SCGs) are expected to be the optimum choice among ac generators in the future. This is due to that SCGs have several advantages over conventional synchronous machines such as higher efficiency, possibility of generating at transmission line voltages because of reduced armature insulation requirements, reduced size and weight in addition to its contribution to stability of power system $[1,2]$. However, SCGs have a complex structure and require materials different from those normally used in conventional machines. At the same time, these machines are characterized by their low inertia and low inherent damping owing to the interactions between their two electro-thermal and damper shields. So, the SCGs require special attention and consideration. Moreover, the very long field winding time constant makes the achievement of acceptable dynamic performance very difficult using excitation control. Therefore, it is necessary to consider only the governor control loop. Enhancing stability of power systems that include SCG has been explored by many authors. This includes the design of a suitable control structure to damp the low oscillation modes [2-7]. The control signals of these control schemes were implemented in the governor control loop of the SCG. This is due to the ineffective nature 
of the excitation control loop of the SCG during transients. However, the governor loop in nature provides relatively lower positive damping in comparison with excitation control loop. Therefore, additional signals need to be used to cater for the lack of positive damping. This is done in this paper by including the Flexible AC Transmission Systems (FACTS) techniques [8].

The philosophy of FACTS is to use power electronics for controlling power flow in a transmission network, thereby allowing the transmission line to be loaded to its full capacity [9]. Shunt reactive power compensator with thyristor controlled device which is one option of FACTS devices that are finding increasing applications [10]. One of its applications is the damping of power system oscillations, which recently has been attracting the interest of many researchers. The ultimate objective of applying a fast acting thyristor phase-controlled reactor in a transmission system is to supply reactive power to increase the transmittable power and to make it more compatible with the prevailing load demand [10]. Thus, this shunt compensator is able to minimize the line overvoltages under light load conditions, and maintain voltage levels under heavy load conditions. For more improvement in system performance this paper suggested a combination of a FLC, in the governor control loop of the SCG, and a TCSR at its terminal bus bar. The performance of the superconducting alternator controlled with FLC has been studied and the results are obtained in comparative form with and without TCSR. The results clearly reveal that with the TCSR a significant improvement in the power system oscillatory performance, an increase in the power system transfer capabilities and a valuable enhancement in both dynamic and transient stability of the system have taken place. Therefore the installation of the proposed scheme can maintain voltage deviation within close tolerances under fault and causes enhancement of both dynamic and transient stability of the system.

\section{SYSTEM MODEL}

The system under consideration is shown in Fig. (1), it consists of a SCG connected to an infinite bus through a transformer and a double circuit transmission line.

The SCG is equipped with a thyristor controlled static compensator at its terminals. The proposed compensator consists of static var compensator of fixed capacitor connected in parallel with bidirectional thyristor air cored reactor as shown in the figure [11]. The SCG is driven by a fast response turbine with fast valving routine. The turbine governor model represents a 3-stage reheat turbine with fast acting electro-hydraulic governor fitted to both the main and interceptor valves. The non-linear differential equations describing the system dynamics are [2]:

$$
\begin{aligned}
& P \Psi_{f}=\omega_{o}\left(V_{f}-i_{f} R_{f}\right) \\
& P \Psi_{d}=\omega_{o}\left(V_{d}+i_{d}\left(r_{a}+r_{e}\right)+\Psi_{q}\right)+\omega \Psi_{q} \\
& P \Psi_{q}=\omega_{o}\left(V_{q}+i_{q}\left(r_{a}+r_{e}\right)+\Psi_{d}\right)+\omega \Psi_{d} \\
& P \Psi_{D 1}=-\omega_{o} i_{D 1} R_{D 1} \\
& P \Psi_{Q 1}=-\omega_{o} i_{Q 1} R_{Q 1} \\
& P \Psi_{D 2}=-\omega_{o} i_{D 2} R_{D 2} \\
& P \Psi_{Q 2}=-\omega_{o} i_{Q}{ }^{R} Q 2
\end{aligned}
$$

Mechanical Equations :

$$
\begin{aligned}
& P \delta=\omega \\
& P \omega=\frac{\omega_{o}}{2 H}(T e-T m)
\end{aligned}
$$

where $T_{e}=\Psi_{d} i_{d}-\Psi_{q} i_{q}$

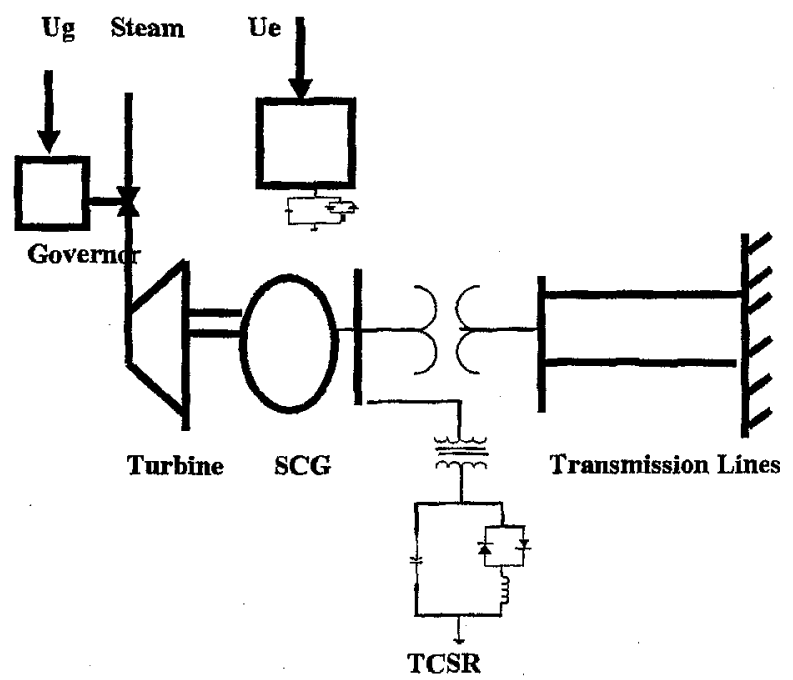

Fig. 1 Schematic diagram of the studied system with TCSR

\section{The Transformer and Transmission lines:}

The transmission system can be approximated by a series lumped resistance and reactance. The $d-q$ 
where,

$$
\begin{aligned}
& V_{b d}^{1}=\left(a_{1} \sin \delta-a_{2} \cos \delta\right) V_{b} \\
& r_{e}{ }^{1}=r_{e} a_{1}-a_{2} \frac{\omega}{\omega_{o}} X_{e} \\
& X_{e}^{1}=r_{e} a_{2}+a_{1} \frac{\omega}{\omega_{o}} X_{e} \\
& c_{1}=\left[\left(\frac{a_{1} \omega_{e} \omega_{o}}{a X_{T}}-\frac{a_{2} X_{e}}{X_{T}}\right) \cos \sigma+\left(\frac{a_{1} X_{e}}{X_{T}}+\frac{r_{e} \omega_{o} a_{2}}{\omega X_{T}}\right) \sin \sigma\right] \\
& c_{2}=\left[\left(\frac{a_{e} \omega_{e}}{\omega X_{T}}-\frac{a_{2} X_{e}}{X_{T}}\right) \sin \sigma+\left(\frac{a_{1}}{X_{T}}+\frac{r_{e} \omega_{o} a_{2}}{\omega X_{T}}\right) \cos \sigma\right] \\
& a_{1}=\left\{1+X_{e}\left(\frac{1}{X t}-\frac{1}{X c}\right)\right\} / \Delta \\
& a_{2}=\left\{r_{e}\left(\frac{\omega_{o}}{\omega}\left(\frac{1}{X t}-\frac{1}{X c}\right)\right\} / \Delta\right. \\
& \Delta=\left\{r_{e} \frac{\omega_{o}}{\omega}\left(\frac{1}{X_{T}}-\frac{1}{X c}\right)\right\}^{2}+\left\{1+x e\left(\frac{1}{X_{T}}-\frac{1}{X c}\right)\right\}^{2}
\end{aligned}
$$

\section{FUZZY CONTROLLER}

A fuzzy logic controller is connected in the governor control loop of the superconducting generator. This controller provides an algorithm which can convert the linguistic control strategy based on expert knowledge into an automatic control strategy. The design of a fuzzy controller mainly involves the selection of the input and output variables, the definition of the membership functions for these variables and the building of a rule database. In this study the FLC has two input variables and generate one output at the governor control loop of the SCG [5]. The controller inputs are the speed deviation from the synchronous speed (speed error), e (k) and the change of the error, $\Delta \mathrm{e}(\mathrm{k})$ at the $\mathrm{k}$ th sampling interval. There are three parts in the FL control system. Fuzzification of input variables, fuzzy rules and defuzzification to generate output [12]. To realize fuzzifications and defuzzification stages, triangular shaped membership functions are selected for all inputs and output variables. In these functions, data interval is divided into seven fuzzy sets. Fig. (3) shows the triangular membership functions used to subdivide the input and output universes.

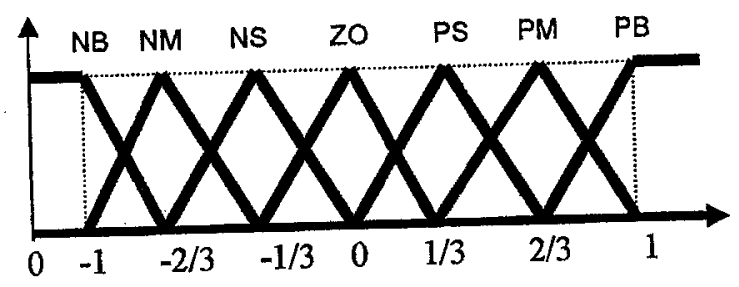

Fig. 3 Membership Functions
Also, all of inputs (before being fuzzified) and output (after being defuzzified) are multiplied with scaling factors $\left(\mathrm{K}_{\mathrm{e}}, \mathrm{K}_{\Delta e}, \mathrm{~K}_{\mathrm{U}}\right)$ that provide adoption between inside the FL controller and the real world outside the controller. These factors play an important role in affecting the performance of the FL controller $[5,12,13]$. In this study, these factors are determined by trial and error. Table 1 shows the fuzzy rules assigned that are used in this study. These nules establish relation between conditions fuzzy sets and the conclusion fuzzy sets. After that the output is aggregated by applying maximum composition method. Then aggregated output is defuzzified by applying centroid method. Lastly, output control signal is multiplied by output scaling factor $\mathrm{K}_{\mathrm{U}}$.

Table 1 Rule Base

\begin{tabular}{|c|c|c|c|c|c|c|c|}
\hline $\begin{array}{c}\Delta \mathrm{e}(\mathrm{K}) \\
\mathrm{e}(\mathrm{K})\end{array}$ & $\mathrm{NB}$ & $\mathrm{NM}$ & $\mathrm{NS}$ & ZO & PS & PM & PB \\
\hline $\mathrm{NB}$ & $\mathrm{NB}$ & $\mathrm{NB}$ & $\mathrm{NB}$ & $\mathrm{NB}$ & $\mathrm{NM}$ & $\mathrm{NS}$ & $\mathrm{ZO}$ \\
\hline $\mathrm{NM}$ & $\mathrm{NB}$ & $\mathrm{NB}$ & $\mathrm{NB}$ & $\mathrm{NM}$ & $\mathrm{NS}$ & $\mathrm{ZO}$ & $\mathrm{PS}$ \\
\hline $\mathrm{NS}$ & $\mathrm{NB}$ & $\mathrm{NB}$ & $\mathrm{NM}$ & $\mathrm{NS}$ & $\mathrm{ZO}$ & $\mathrm{PS}$ & $\mathrm{PM}$ \\
\hline $\mathrm{ZO}$ & $\mathrm{NB}$ & $\mathrm{NM}$ & $\mathrm{NS}$ & $\mathrm{ZO}$ & $\mathrm{PS}$ & $\mathrm{PM}$ & $\mathrm{PB}$ \\
\hline PS & NM & NS & ZO & PS & PM & PB & PB \\
\hline PM & NS & ZO & PS & PM & PB & PB & PB \\
\hline PB & ZO & PS & PM & PB & PB & PB & PB \\
\hline
\end{tabular}

\section{SIMULATION RESULTS AND DISCUSSION}

A simulation program using a non-linear system model has been carried out to investigate the effectiveness of the proposed Thyristor Controlled Series Reactor Compensator under $120 \mathrm{~ms}$ three phase short circuit at the transformer high voltage side. Figs.(4)-(6) show the simulation results in a comparative form when FLC is applied in the governor control loop of the SCG and with or without TCSR at its terminals at a power of $0.8 \mathrm{p} . \mathrm{u}$ for lag, lead and unity power factors respectively. It is obvious that the system with TCSR returns to its original operating conditions smoothly and quickly than the system without TCSR. This means that the system overshoot, rise time and the settling time were minimized. Also, the application of this scheme increases the stability reserve indicated by the reduction in the rotor first swing and a fast recovery of terminal voltage. So, it is seen that TCSR provides the power system with a sufficient amount of positive damping to suppress the oscillations most effectively and better dynamic and transient performance is obtained. Briefly, the obtained results assured the adaptive nature of TCSR in damping the system oscillations most effectively and better dynamic and transient performance is obtained. 
equations relating the machine terminals to the large power system are:

$$
\begin{aligned}
& V_{d}=V_{b} \sin \delta-x_{e} i_{q}+r_{e} i_{d} \\
& V_{q}=V_{b} \cos \delta+X_{e} i_{d}+r_{e} i_{q} \\
& \text { where, } X_{e}=X_{T}+X_{L} \text { and } R_{e}=R_{T}+R_{L}
\end{aligned}
$$

\section{The Turbine and Governor system :}

The model of the three-stage steam turbine with reheat and the electro-hydraulic governor considered in this study follows the IEEE standard representation and the special IEEE recommendations for the turbine and governor of the SCG:

$$
\begin{aligned}
& P Y_{H P}=\left(G_{M} P_{o}-Y_{H P}\right) / T_{H P} \\
& P Y_{R H}=\left(Y_{H P}-Y_{R H}\right) / T_{R H} \\
& P Y_{I P}=\left(G_{I} Y_{R H}-Y_{I P}\right) / T_{I P} \\
& P Y_{L P}=\left(Y_{I P}-Y_{L P}\right) / T_{L P} \\
& T_{m}=F_{H P} Y_{H P}+F_{I P} Y_{I P}+F_{L P} Y_{L P} \\
& P G_{M}=\left(U_{G M}-G_{M}\right) / T_{G M} \\
& P G_{I}=\left(U_{G I}-G_{I}\right) / T_{G I}
\end{aligned}
$$

where the position and rate limits are,

$$
0<\mathrm{G}_{\mathrm{M}}, \mathrm{G}_{\mathrm{I}}<1.0 \text { and }
$$

$-6.7<\mathrm{PG}_{\mathrm{M}}, \mathrm{PG}_{\mathrm{r}}<6.7 \mathrm{p.w} / \mathrm{sec}$

The parameters of the system are given in the Appendix.

\section{METHODOLOGY OF THE TCSR COMPENSATOR}

The compensator scheme used in this study is the thyristor controlled static reactive power compensator which is one member of FACTS family and is assumed to be of fixed capacitor connected in parallel with bi-directional thyristor air cored reactor as shown in Fig(1). This compensator is connected at the terminals of the superconducting generator. The firing angle control range of this scheme is from $0^{\circ}$ to $180^{\circ}$. The ultimate objective of applying shunt compensation in a transmission system is to supply reactive power to increase the transmittable power and to make it more compatible with the prevailing load demand. Thus, the shunt compensator able to minimize the line over- voltages under light load conditions, and maintain voltage levels under heavy load conditions. Therefore, the shunt controller is a good way to control the voltage at and around the point of connection. When this compensator scheme is applied the tie-lines Equations (10), (11), with the aid of the phasor diagram shown in Fig.(2), becomes [11]:

$$
\begin{aligned}
& e_{d}=V_{b} \sin \delta-\frac{\omega}{\omega_{o}} X_{e} i_{q}^{1}+r_{e} i_{d}^{1} \\
& e q=V_{b} \cos \delta+\frac{\omega}{\omega_{o}} X_{e} i_{d}^{1}+r_{e} i_{q}^{1}
\end{aligned}
$$

where, $i_{d}^{1}=i_{d}-i_{r d}-i_{c d}, i_{q}^{1}=i_{q}-i_{r q}-i_{c q}$

With the aid of the phasor diagram, we can conclude the next equations.

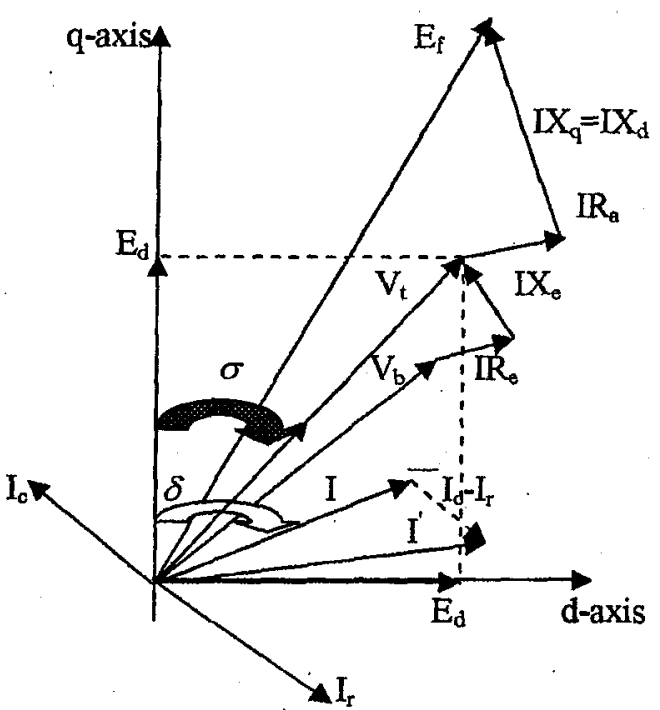

Fig. 2 Phasor diagram of the studied system with TCSR

$$
\begin{aligned}
& i_{r d}=\frac{\omega_{o}}{\omega}\left(\frac{1}{X_{T}}\right)\left(e_{q}-E_{1} \cos \sigma\right) \\
& i_{r q}=-\frac{\omega_{o}}{\omega}\left(\frac{1}{X_{T}}\right)\left(e_{d}-E_{t} \sin \sigma\right) \\
& i_{c d}=-\left(\frac{\omega_{o}}{\omega X c}\right) e_{q}, i_{c q}=\left(\frac{\omega_{o}}{\omega X c}\right) e_{d}
\end{aligned}
$$

where

$$
\begin{gathered}
\sigma=\tan ^{-1}\left(e_{d} / e_{q}\right) \\
E_{T}=V_{T}\left(\frac{2 \alpha-\sin 2 \alpha}{2 \pi}\right) \\
0<\alpha \leq \pi, \quad \alpha: \text { firing angle }
\end{gathered}
$$

With the firing control of the thyristors, it can change its apparent reactance smoothly and rapidly. This characteristic meets the demands of modern power systems that must operate flexibly and react quickly [11].

From Eqns. (21)-(23) into Eqns. (19) and (20), the direct and quadrature axis voltages are :

$$
\begin{aligned}
& e_{d}=v_{b d}^{1}+r_{e}^{1} i_{d}-X_{e}^{1} i_{q}+c_{1} E_{t} \\
& e_{q}=v_{b q}^{1}+r_{e}^{1} i_{q}+X_{e}^{1} i_{d}+c_{2} E_{t}
\end{aligned}
$$




\section{CONCLUSION}

The paper presents the development and implementation of the thyristor controlled static compensator at the terminals of a superconducting generator. Controller performance is investigated using non-linear time domain simulations. The comparative simulation results verified that the proposed scheme can improve the power system performance as it is capable of providing sufficient damping to the system oscillations and improving the steady state performance even when operating conditions change. This FACT device brings a fast recovery of terminal voltage over a wide range of operating conditions under three-phase short circuit fault. Therefore, the thyristor controlled compensation offers a powerful means increasing and controlling power transfer. Based on this study and from the comparative results, it can be concluded that the thyristor controlled static compensator is superior for improvements of the transient stability of the system under consideration.

\section{Appendix :}

The following data in p.u. of a superconducting turbo-generator are chosen for digital simulation : SCG parameters :

$$
\begin{aligned}
& 2000 \text { MVA, } 1700 \mathrm{MW}, 3000 \text { r.p.m } \\
& X_{d}=X_{q}=0.0453 \text { p.u., } X_{f}=0.541 \text { p.u. , } \\
& \mathrm{X}_{\mathrm{KD} 1}=\mathrm{X}_{\mathrm{KQ1}}=0.2567 \text { p.u., } \mathrm{X}_{\mathrm{fKD2}}=0.3398 \text { p.u. } \\
& \mathrm{X}_{\mathrm{a} F}=\mathrm{X}_{\mathrm{EKD1}}=\mathrm{X}_{\mathrm{aD1}}=\mathrm{X}_{\mathrm{aD2} 2}=\mathrm{X}_{\mathrm{XD1} 1 \mathrm{KD} 2}=0.237 \text { p.u., } \\
& \mathrm{X}_{\mathrm{QQ1}}=\mathrm{X}_{\mathrm{aQ2} 2}=\mathrm{X}_{\mathrm{KQ1KQ2}}=0.237 \text { p.u. } \\
& R_{K D 1}=R_{K Q 1}=0.01008 \text { p.u., } R_{\mathrm{q}}=0.003 \text { p.u., } \\
& \mathrm{R}_{\mathrm{KD2} 2}=\mathrm{R}_{\mathrm{KQ2}}=0.00134 \text { p.u. } \\
& \mathrm{H}=3.0 \mathrm{KWS} / \mathrm{KVA}
\end{aligned}
$$

Transmission System Parameters :

$X_{\mathrm{T}}=0.15$ p.u. , $R_{\mathrm{T}}=0.003$ p.u., $\mathrm{X}_{\mathrm{L}}=0.05$ p.u.,

$R_{L}=0.005 p . u$.

Parameters of Governor and Turbine :

$\mathrm{T}_{\mathrm{HP}}=0.1 \mathrm{sec}, \mathrm{F}_{\mathrm{HP}}=0.26, \mathrm{~T}_{\mathrm{TP}}=0.3 \mathrm{sec}, \mathrm{F}_{\mathrm{PP}}=0.42$,

$\mathrm{T}_{\mathrm{LP}}=0.3 \mathrm{sec}, \mathrm{F}_{\mathrm{LP}}=0.32, \mathrm{~T}_{\mathrm{RH}}=10 \mathrm{sec}, \mathrm{T}_{\mathrm{GM}}=\mathrm{T}_{\mathrm{G}}=0.1$

$\sec , P_{0}=1.2$ P.U.

\section{REFERENCES}

[1] M. A. S. Alyan and Y. H. A. Rahim, "The role of governor control in transient stability of Superconducting turbo generators", IEEE Trans., 1987, EC-2, pp.38-46.

[2] G. A. Morsy, A. Kinawy and S. M. Osheba, "Frequency Domain analysis of a Superconducting Generator", Electrical Power System Research (30), 1994, pp.107-113.
[3] G. A. Morsy, H. Khattab , A. M. Kinawy, "Design of a PI controller for a superconducting generator", Eng. Research Blue., Vol. 23, No. 1, Fac. Of Eng., Men. Univ., Jan 2000, pp. 61-77.

[4] G. A. Morsy, T. A. Mohammed, "An ANN based PI controller for a superconducting generator", Eng. Research Journal, Faculty of Eng., Minufiya Univ., Egypt., Vol. 24, No. 3, July 2001, pp.113125.

[5] H.A.Khattab, G.A. Morsy, S. M. Osheba and A. M. Kinawy, "Fuzzy PI Controller For a Superconducting Generator", MEPs, Vol.2,July 2005,pp.7-11.

[6] G. A. Morsy, "Validation of a Flexible Controller for a Superconducting Generator", Eng. Research Journal (ERJ),Faculty of Eng., Minufiya Univ., Egypt Vol.25,No.2, April 2002,pp. 187-199.

[7] G. A. Morsy, H. Yasin and A. A. Khattab, " Robust Controller Design for A Superconducting Generator", MEPCON' 2003, Minoufiya Univ., Shebin El-Kom, Egypt, Dec.16-18, 2003, pp. 131-136.

[8] X. R. Chen et al., "Controlled Series Compensation for Improving The Stability Of Multi-Machine Power System", IEE Proc.-C, vol.142, No.4, July 1995, pp. 361-366.

[9] Mohamed Z. El-sadek, "Power System Voltage stability and Power quality", Book, Mukhtar Press, Assiut, Egypt, 2003.

[10] C.S.Kumble et al., "Output Feedback TCSC Controllers To improve Damping Of Meshed multi-machine power Systems", IEE Proc.C,vol.144,No.3,May 1997,pp. 243-248.

[12] A. S. R.Murty et al.,"Performance Evaluation of Static VAR Compensated System With Auxiliary Controls", Electric Machines and Power Systems, 1991,pp. 251-270.

[11] P. K. Dash et al., " Improvement Of The Performance of A Superconducting Turbogenerator Through Use of A Controllable Reactive Power Compensator", Electric Machines and Electromechanics, 1977,pp.73-86

[12] P. Hoang and K. Tomsovic, "Design and analysis of an adaptive fuzzy power system stabilizer", IEEE Trans. On Energy Conversion, Vol. 11, No.2., June 1996, pp. 455-461.

[13] W. M. Refeay, "Fuzzy logic power system stabilizer for multi-machine power system", MEPCON'2000, Ain-Shams Univ., Cairo, Egypt, pp 367-372, 2000. 

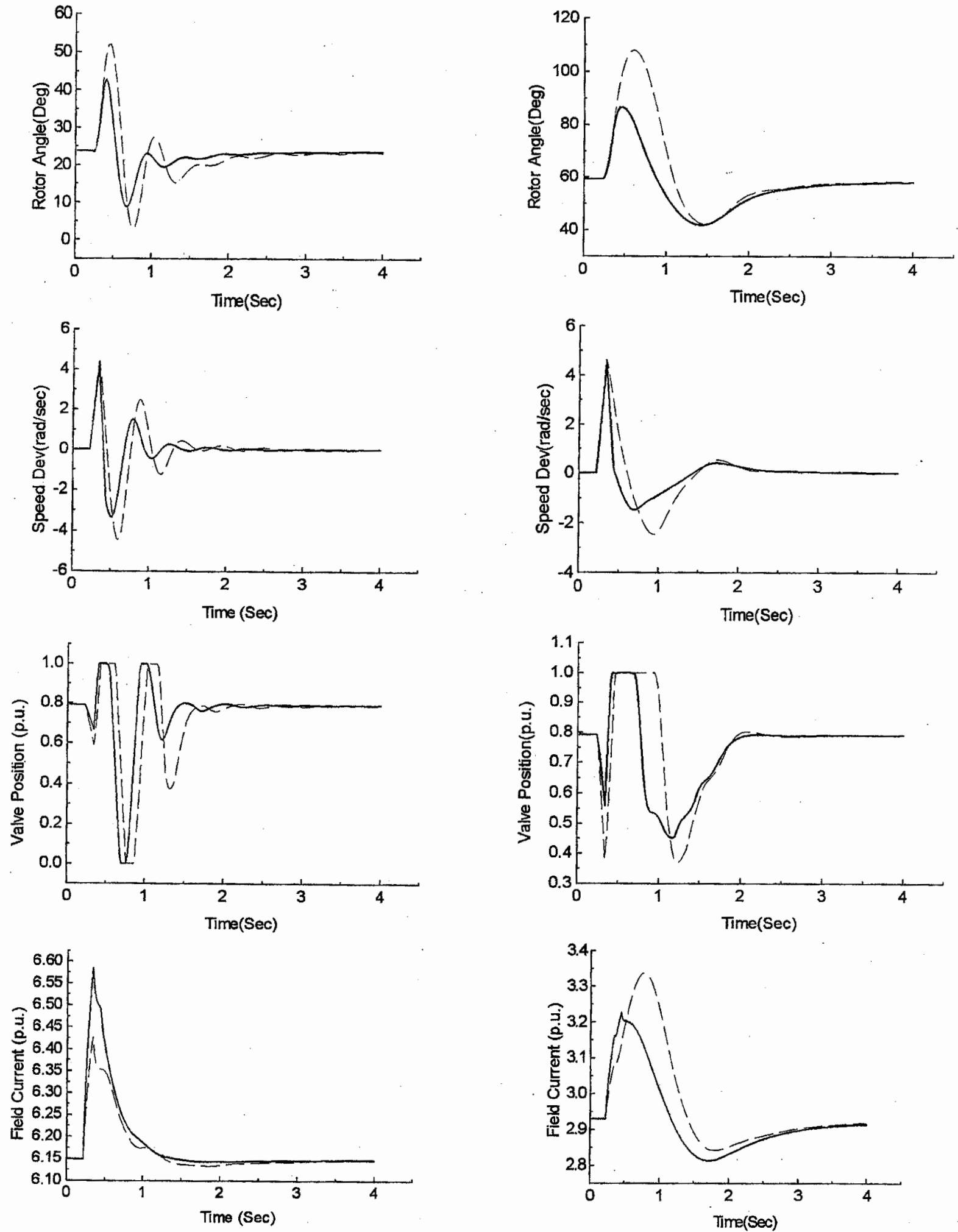

Fig. 4 Response to a 3-Phase Short Circuit for 120ms 0.8 Lag P.F.

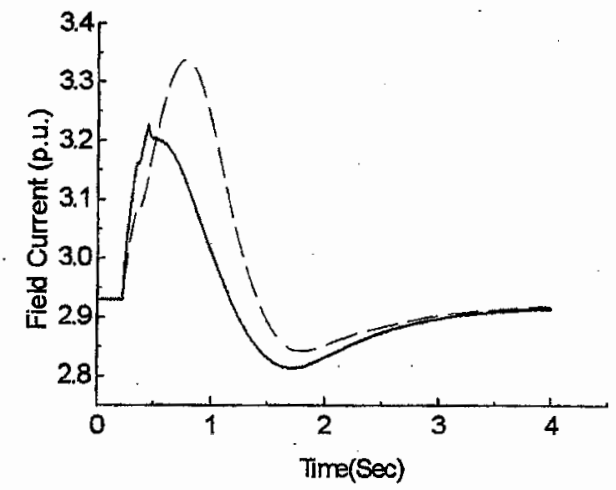

Fig. 5 Response to a 3-Phase Short Circuit for 120ms 0.8 Lead P.F.

SCG With FLC + TCSR at its terminals
SCG with FLC 

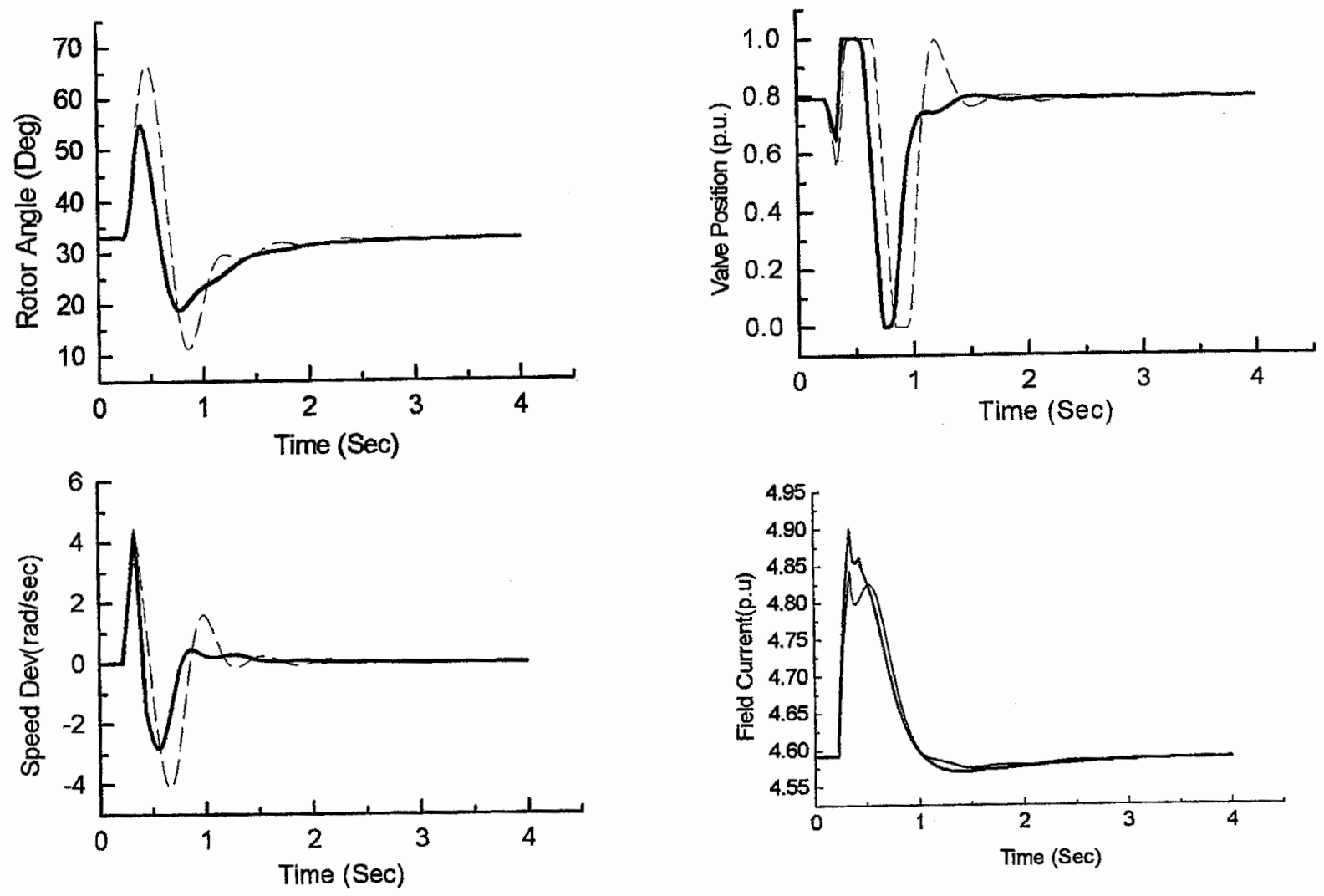

Fig. 6 Response to a 3-Phase Short Circuit for 120-ms Unity P.F.

SCG With FLC + TCSR at its terminals

........... SCG with FLC 